\title{
ASSESSING SCREENING PRACTICES AMONG HEALTH CARE WORKERS AT A TERTIARY-CARE HOSPITAL IN SAO PAULO, BRAZIL
}

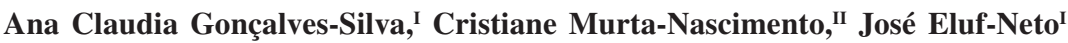

doi: 10.1590/S1807-59322010000200006

Gonçalves-Silva AC, Murta-Nascimento C, Eluf-Neto J. Assessing screening practices among health care workers at a tertiary-care hospital in Sao Paulo, Brazil. Clinics. 2010;65(2):151-5.

OBJECTIVE: To ascertain the extent to which screening procedures (with and without evidence of effectiveness) are practiced among health care workers at a tertiary-care hospital in Sao Paulo, Brazil.

METHODS: From February 2001 to September 2003, a cross-sectional study involving physicians, nurses and nursing assistants (aged 40 to 69 years) was carried out at a tertiary-care hospital in the city of Sao Paulo, Brazil. Subjects were interviewed using a questionnaire that addresses 17 procedures with grades of recommendation of A, B, C, D or E, in accordance with the 1996 United States Preventive Services Task Force guidelines for routine screening.

RESULTS: Of the 333 health care workers included, 228 (68.5\%) were female. The mean age was 48.8 (SD 6.6 years). Most subjects had undergone screening for hypertension (blood pressure measurement) and lipid abnormalities (cholesterol testing). Screening for breast and cervical cancer was common among females. Resting electrocardiography, serum glucose testing, urine tests, chest X-rays and serum prostate-specific antigen testing were also quite common. However, only $6(1.8 \%)$ of the subjects had undergone screening for colorectal cancer (fecal occult blood test or sigmoidoscopy).

CONCLUSIONS: A sizeable proportion of health care workers underwent screening procedures that are not recommended or for which there was insufficient evidence of a benefit. Conversely, certain recommended procedures were performed on a small proportion of such workers. These results indicate that the Brazilian National Ministry of Health must develop nationwide evidence-based screening recommendations and disseminate such recommendations among health care professionals in Brazil.

KEYWORDS: Cross-sectional studies; Prevention; Health personnel; Hospitals; Brazil.

\section{INTRODUCTION}

Interest in using screening procedures to identify diseases in asymptomatic individuals began to increase in the late 1950s. However, it was only in the early 1980s that health authorities began to set up task forces charged with devising criteria to assess the effectiveness of these and other procedures. ${ }^{1,2}$

\footnotetext{
${ }^{\mathrm{I}}$ Departamento de Medicina Preventiva, Faculdade de Medicina da Universidade de São Paulo - Sao Paulo/SP, Brazil

II Servei d'Avaluació i Epidemiologia Clínica, Hospital del Mar-IMAS Barcelona, Spain

Email: jelufnet@usp.br

Tel.: 55113061.8278

Received for publication on October 16, 2009

Accepted for publication on November 05, 2009
}

The potential benefits of screening include the early detection of disease, the prevention of serious illness or disability and improved survival. ${ }^{3,4}$ However, not all screening procedures have shown benefits, and some may cause harm to the health of the individual. ${ }^{5}$

Various studies have shown that certain screening practices are performed in an inappropriate manner. ${ }^{6-9}$ For instance, although many females in developing countries undergo an annual Papanicolaou (Pap) smear, there are also many who have never had one. In addition, urine tests, electrocardiography (ECG) and blood workups are frequently carried out as screening procedures, despite the fact that there is no evidence that these tests provide benefits. In contrast, other procedures that are known to be effective, such as the fecal occult blood test (FOBT) for colorectal cancer in individuals 50 years of age or older, are rarely 
performed.

Physicians and other health care workers (HCWs) are a direct source of health information for the population. Therefore, it is important that the information they disseminate be accurate and that the screening procedures they recommend be appropriate. In addition, previous studies have reported that the personal health habits of physicians are major predictors of their counseling practices. ${ }^{8,10}$

Brazil lacks a nationwide screening program, and the guidelines regarding this issue are conflicting. In addition, little is known about the personal health habits of HCWs in Brazil. Therefore, the aim of the present study was to ascertain the extent to which screening procedures (with and without evidence of effectiveness) are practiced among HCWs at a tertiary-care hospital in Sao Paulo, Brazil.

\section{METHODS}

From February 2001 to September 2003, a crosssectional study involving HCWs was carried out at the largest tertiary-care facility (with approximately 2,200 beds) in Latin America, located in the city of Sao Paulo, Brazil. The study population was composed of physicians, nurses and nursing assistants who worked at three institutes and who together included $82.5 \%(4,333)$ of the HCWs employed by the hospital.

The inclusion criteria were being 40-69 years of age and an employee of the hospital. Individuals on leave were ineligible. Subjects were randomly selected from a list of physicians, nurses and nursing assistants. Sample size was calculated based on the expected frequency of three screening procedures: Pap smear (among females); breast self-examination (among females); cholesterol screening (among both genders).

The selected sample comprised 170 nursing assistants (162 females and 8 males), 26 nurses (all female) and 137 physicians (40 females and 97 males). Face-toface interviews were conducted by trained personnel. A structured questionnaire was developed specifically for use in the present study. The questionnaire was designed to collect data related to sociodemographic characteristics, medical history and family history of certain diseases, as well as a list of screening procedures. For each procedure, respondents were asked to provide the age at which they were first tested, the number of times they had undergone the test and the time elapsed since the last test. We defined a screening procedure as any procedure to which subjects had been submitted of their own volition or as part of prenatal care or a work-related medical examination. We attempted to clarify the differences between screening practices and diagnostic tests for the participants. The questionnaire included procedures with grades of recommendation of A, B, C, D or E, in accordance with the 1996 edition of the United States Preventive Services Task Force (USPSTF) guidelines for routine screening (Chart 1). ${ }^{2}$ The 17 procedures analyzed were divided into three groups:

1. screening for diabetes and cardiovascular diseases, as well as for their risk factors: serum glucose measurement; blood pressure measurement; cholesterol measurement; resting ECG;

2. screening for cancer: FOBT, digital rectal examination and sigmoidoscopy (for colorectal cancer); mammography, breast self-examination and clinical breast examination (for breast cancer); Pap smear (for cervical cancer); prostate-specific antigen (PSA) test and digital rectal examination (for prostate cancer);

3. screening for other diseases: urine test; tuberculin skin test (the Mantoux test); chest X-ray; bone densitometry.

Data were entered twice, by two different operators, into a database using the Epi Info program. For each screening procedure, we estimated the proportion of HCWs who had undergone the procedure at least once, and we calculated the corresponding $95 \%$ confidence intervals.

The present study was approved by the local research ethics committee. All participants provided written informed consent prior to the initiation of the interview process.

\section{RESULTS}

Of the 364 randomly selected HCWs, 22 (6\%) could not be located after three attempts and $9(2 \%)$ declined to participate. Therefore, the final sample consisted of 333 HCWs, of whom 228 (68.5\%) were female. The mean age was 48.8 years (SD 6.6 years). Sociodemographic characteristics of the participants are summarized in Table 1.

The prevalence of screening practices is shown in Table 2. For $204(61.3 \%)$ of the respondents, the determination of serum cholesterol levels had been performed as a screening procedure at least once. Five males and 95 females began to monitor their cholesterol levels before the ages of 35 and 45 years, respectively. Resting ECG as a screening procedure was reported by 159 (47.7\%) subjects, and 25\% reported having undergone ECG more than six times.

Regarding screening for colorectal cancer, only 6 subjects reported having been screened with the FOBT or sigmoidoscopy (Table 2). Of the 228 females, 164 (71.9\%) had undergone a mammography as a screening procedure, $219(96.1 \%)$ had undergone their first mammography before the age of 50 and $216(94.7 \%)$ had experienced a Pap smear at least once (Table 2). Of the 105 males, $70(66.7 \%)$ had undergone PSA testing and 34 (32.4\%) had been submitted to a digital rectal examination. 
Chart 1 - 1996 United States Preventive Services Task Force recommendations* and the screening procedures analyzed

\begin{tabular}{|c|c|c|}
\hline Grade** & Recommendation & Test or procedure evaluated \\
\hline A & $\begin{array}{l}\text { There is good evidence to support the recommenda- } \\
\text { tion that the condition be specifically considered in a } \\
\text { periodic health examination. }\end{array}$ & $\begin{array}{l}\text { - to screen for hypertension, blood pressure measurement for all persons } \\
\geq 21 \text { years of age } \\
\text { - to screen for breast cancer, mammography alone or mammography with } \\
\text { clinical breast examination for females 50-69 years of age } \\
\text { - to screen for cervical cancer, Papanicolaou smear } \\
\text { - to screen for infection with Mycobacterium tuberculosis, tuberculin skin } \\
\text { testing for all persons at increased risk (including health care workers) }\end{array}$ \\
\hline B & $\begin{array}{l}\text { There is fair evidence to support the recommendation } \\
\text { that the condition be specifically considered in a peri- } \\
\text { odic health examination. }\end{array}$ & $\begin{array}{l}\text { - to screen for lipid abnormality, serum cholesterol determination for all } \\
\text { males 35-65 years of age and all females } 45-65 \text { years of age } \\
\text { - to screen for colorectal cancer, fecal occult blood testing for all persons } \\
\geq 50 \text { of age }\end{array}$ \\
\hline $\mathrm{C}$ & $\begin{array}{l}\text { There is insufficient evidence to recommend for or } \\
\text { against the inclusion of the condition in a periodic } \\
\text { health examination, although recommendations may be } \\
\text { made on other grounds. }\end{array}$ & $\begin{array}{l}\text { - to screen for asymptomatic coronary artery disease, resting electrocardiog } \\
\text { raphy for males and females } \\
\text { - to screen for diabetes mellitus, serum or plasma glucose determination in } \\
\text { non-pregnant adults } \\
\text { - to screen for breast cancer, clinical breast examination for females 50-69 } \\
\text { years of age } \\
\text { - teaching breast self-examination in the periodic health examination } \\
\text { - to screen for colorectal cancer, digital rectal examination } \\
\text { - to screen for asymptomatic bacteriuria, leukocyte esterase or nitrite testing } \\
\text { in urine for ambulatory elderly females or females with diabetes } \\
\text { - to screen for osteoporosis, bone densitometry in asymptomatic, postmeno- } \\
\text { pausal females }\end{array}$ \\
\hline $\mathrm{D}$ & $\begin{array}{l}\text { There is fair evidence to support the recommendation } \\
\text { that the condition be excluded from consideration in a } \\
\text { periodic health examination. }\end{array}$ & $\begin{array}{l}\text { - to screen for lung cancer, chest X-ray } \\
\text { - to screen for prostate cancer, prostate specific antigen testing or digital } \\
\text { rectal examination }\end{array}$ \\
\hline E & $\begin{array}{l}\text { There is good evidence to support the recommendation } \\
\text { that the condition be excluded from consideration in a } \\
\text { periodic health examination. }\end{array}$ & - none \\
\hline
\end{tabular}

Source: United States Preventive Services Task Force (USPSTF). ${ }^{2}$

*Some of these recommendations have changed in the more recent versions of the USPSTF guidelines. For up-to-date information, access the USPSTF webpage (http://www.ahrq.gov/clinic/uspstfix.htm).

**Grade of recommendation.

More than $50 \%$ of the subjects reported having undergone other screening procedures, such as a chest X-ray and urine test. For 75 (32.9\%) of the females (all of whom were $\leq 64$ years of age at the time of the test), bone densitometry had been performed at least once.

\section{DISCUSSION}

This is the first study to investigate personal screening practices in a random sample of HCWs at a tertiary-care hospital in Brazil. We observed great variability in these screening practices.

According to the 1996 USPSTF guidelines, the recommended methods of screening for cardiovascular diseases are measurement of blood pressure (for adults over 20 years of age) and determination of serum cholesterol levels (for males $\geq 35$ years of age and for females $\geq 45$ years of age). More than $70 \%$ of the HCWs investigated in the present study reported having had their blood pressure measured as a screening procedure. It should be noted that this prevalence might have been underestimated given that the measurement of blood pressure in routine clinical appointments might not have been perceived as a screening practice. However, more than $38 \%$ of the HCWs of both genders had never undergone serum cholesterol measurement as a screening procedure. This is somewhat higher than the $23 \%$ reported by the Behavioral Risk Factor Surveillance System for HCWs in the United States in 2001. ${ }^{11}$ Although resting ECG is not recommended in asymptomatic individuals without risk factors for cardiovascular diseases, we observed that nearly $50 \%$ of the participants had been submitted to this test. The exercise 
Table 1 - Distribution of health care workers according to sociodemographic characteristics, Sao Paulo, Brazil, 2001-2003

\begin{tabular}{lcc}
\hline Characteristic & $\mathrm{N}$ & $\%$ \\
\hline Total & 333 & \\
Gender & & \\
$\quad$ Female & 228 & 68.5 \\
$\quad$ Male & 105 & 31.5 \\
Age group (years) & & \\
$\quad$ 40-49 & 202 & 60.7 \\
50-59 & 100 & 30.0 \\
60-69 & 31 & 9.3 \\
Level of education* & & \\
$\quad$ Elementary school & 33 & 10.0 \\
$\quad$ High school (incomplete) & 35 & 10.6 \\
High school (complete) & 81 & 24.5 \\
College (incomplete) & 15 & 4.5 \\
College (complete) & 166 & 50.3 \\
Marital status & & \\
$\quad$ Married & 177 & 53.2 \\
Single & 79 & 23.7 \\
Separated/divorced & 56.8 \\
Widowed & 56.1 \\
Occupation & 21 & 16.8 \\
Physician & & 6.3 \\
$\quad$ Nurse & & \\
$\quad$ Nursing Assistant & & \\
\hline
\end{tabular}

*No data for 3 subjects. stress test, for which there is also no evidence of a benefit in terms of a reduction in mortality, had been performed on $8 \%$ of the respondents (data not shown).

The USPSTF recommends the FOBT as a screening tool for colorectal cancer in all individuals $\geq 50$ years of age. Of the 333 HCWs evaluated in the present study, 131 (39\%) were in this age group. However, only $3(1 \%)$ reported having undergone this test as a screening procedure. The 2008 Behavioral Risk Factor Surveillance System report ${ }^{11}$ showed that $20.9 \%$ of the participants aged $\geq 50$ years had undergone the FOBT within the past two years and that $61.8 \%$ had undergone sigmoidoscopy or colonoscopy.

The 1996 USPSTF recommendation for breast cancer screening is mammography (with or without clinical breast examination) for females $\geq 50$ years of age, ${ }^{2}$ although an update of the guidelines recommends that the age range be expanded to females $\geq 40$ years of age. ${ }^{12}$ In our sample, $28 \%$ of the females reported that they had never undergone this test. Although the evidence is insufficient to recommend breast self-examination as a screening practice, $88 \%$ of the female HCWs reported performing this examination on themselves, routinely.

Among the female HCWs evaluated, the prevalence of having had at least one Pap smear was $95 \%$. This prevalence was much higher than the $69 \%$ and $86 \%$ reported, respectively, by Nascimento et al. ${ }^{7}$ and Pinho et al. ${ }^{13}$ for females in the city of São Paulo.

Although the 1996 and 2008 USPSTF guidelines do

Table 2 - Screening practices among health care workers in a tertiary-care hospital in Sao Paulo, Brazil, 2001-2003

\begin{tabular}{lcc}
\hline & & Screening practice \\
Screening procedur & N (\%) & At least once \\
\cline { 2 - 3 } & & $260(78.1)$ \\
Serum glucose measurement (for diabetes mellitus) & $73(21.9)$ & $236(70.9)$ \\
Blood pressure measurement (for hypertension) & $97(29.1)$ & $204(61.3)$ \\
Serum cholesterol determination (for lipid abnormality) & $129(38.7)$ & $159(47.7)$ \\
Resting electrocardiography (for asymptomatic coronary artery disease) & $174(52.3)$ & $4(1.2)$ \\
Fecal occult blood test (for colorectal cancer) & $329(98.8)$ & $2(0.6)$ \\
Sigmoidoscopy (for colorectal cancer) & $331(99.4)$ & $3(0.9)$ \\
Digital rectal examination (for colorectal cancer) & $330(99.1)$ & $164(71.9)$ \\
Mammography* (for breast cancer) & $64(28.1)$ & $200(87.7)$ \\
Breast self-examination* (for breast cancer) & $28(12.3)$ & $170(74.6)$ \\
Clinical breast examination* (for breast cancer) & $58(25.4)$ & $216(94.7)$ \\
Papanicolaou smear* (for cervical cancer) & $12(5.3)$ & $69(65.7)$ \\
Prostate-specific antigen test** (for prostate cancer) & $36(34.3)$ & $34(32.4)$ \\
Digital rectal examination (for prostate cancer)** & $71(67.6)$ & $190(57.1)$ \\
Chest X-ray (for lung cancer) & $143(42.9)$ & $169(50.8)$ \\
Urine test (for asymptomatic bacteriuria) & $164(49.2)$ & $75(32.9)$ \\
Bone densitometry* (for osteoporosis) & $153(67.1)$ & $83(24.9)$ \\
Mantoux test (for infection with Mycobacterium tuberculosis) & $250(75.1)$ & \\
\hline
\end{tabular}

*Females only. **Males only. 
not recommend PSA testing as a screening procedure, $67 \%$ of the male HCWs who participated in the present study reported having had the test. A high prevalence of PSA testing (78.6\%) was also reported among 135 lecturers and professors $\geq 51$ years of age at a medical school in Belo Horizonte, Brazil. ${ }^{14}$

Regarding the other screening procedures investigated in the present study (urine test, Mantoux test, chest X-ray and bone densitometry), a large proportion of HCWs reported having undergone these tests several times. However, except for bone densitometry (recently given a grade B recommendation among females $\geq 65$ years of age), the other tests are not recommended.

The present study has several limitations. First, it was conducted at a public, tertiary-care teaching hospital. Therefore, it is not possible to generalize the results to HCWs at other institutions. Second, our sample was composed of a heterogeneous group of HCWs and physicians in various specialties. It has previously been reported that the beliefs of HCWs concerning the effectiveness of different screening practices may vary by specialty. ${ }^{15}$ Finally, we used the 1996 USPSTF recommendations as the gold standard because there are no Brazilian guidelines for many of these screening procedures. However, there are guidelines established by other foreign institutions that differ from the USPSTF guidelines.

\section{CONCLUSIONS}

The present study investigated screening practices among HCWs at a tertiary-care hospital. Findings showed that a great proportion of the subjects had undergone tests that are considered unnecessary or for which there is insufficient evidence of their usefulness as screening tools, whereas certain recommended tests had been neglected. Because there are no standardized screening programs in Brazil and individuals are, therefore, submitted to screening tests without sufficient knowledge of their effectiveness, it is important that the public authorities in Brazil review the scientific evidence regarding the benefits and hazards of screening procedures, develop guidelines that address these issues and disseminate the information among HCWs.

\section{ACKNOWLEDGMENTS}

Ana Claudia Camargo Gonçalves da Silva is the recipient of Masters fellowship grants from the Conselho Nacional de Desenvolvimento Científico e Tecnológico (CNPq, National Council for Scientific and Technological Development; grant no. 131142/2003-8) and the Fundação de Amparo à Pesquisa do Estado de São Paulo (FAPESP, Foundation for the Support of Research in the State of São Paulo; grant no. 03/05278-5).

\section{REFERENCES}

1. Canadian Task Force on the Periodic Health Examination. The periodic health examination. Can Med Assoc J. 1979;121:1193-254.

2. U.S. Preventive Services Task Force. Guide to clinical preventive services. 2nd ed. Baltimore: Williams \& Wilkins; 1996.

3. Morrison AS. Screening in Chronic Disease. 2nd ed. New York: Oxford University Press; 1992.

4. Eluf-Neto J. Rastreamento em Medicina Interna. In: Martins MA, Carrilho FJ, Alves VAF, Castilho EA, Cerri GG, Wen CL. Clínica Médica. Barueri: Ed. Manole Ltda, 2009. v. 7, p. 368-73.

5. Stewart-Brown S, Farmer A. Screening could seriously damage your health. BMJ. 1997;314:533-4.

6. Hall JA, Palmer H, Orav EJ, Hargraves JL, Wright EA, Louis TA. Performance quality, gender, and professional role. A study of physicians and nonphysicians in 16 ambulatory care practices. Med Care. 1990; 28:489-501.

7. Nascimento CM, Eluf-Neto J, Rego RA. Pap test coverage in Sao Paulo municipality and characteristics of the women tested. Bull Pan Am Health Organ. 1996;30:302-12.

8. Frank E, Brogan DJ, Mokdad AH, Simões EJ, Kahn HS, Greenberg RS. Health-related behaviors of women physicians vs other women in the United States. Arch Intern Med. 1998;158:342-8.
9. Toyry S, Rasanen K, Kujala S, Aarimaa M, Juntunen J, Kalimo R, et al. Self-reported health, illness, and self-care among Finnish physicians: a national survey. Arch Fam Med. 2000;9:1079-85.

10. Schwartz JS, Lewis CE, Clancy C, Kinosian MS, Radany MH, Koplan JP. Internists' practices in heath promotion and disease prevention. Ann Intern Med. 1991;114:46-54.

11. Centers for Disease Control and Prevention [CDC]. Behavioral Risk Factor Surveillance System. Available online: http://www.cdc.gov/ brfss/. Accessed 2009 Oct 1.

12. U.S. Preventive Services Task Force. Recommendations. Available online: http://www.ahrq.gov/clinic/uspstfix.htm\#Recommendations. Accessed 2009 Oct 1.

13. Pinho AA, Franca Junior I, Schraiber LB, D'Oliveira AF. Cobertura e motivos para a realização ou não do teste de Papanicolaou no Município de São Paulo. Cad Saude Publica. 2003;19:S303-13.

14. Miranda PS, Cortes Mda C, Martins ME, Chaves PC, Santarosa RC Practice of precocious diagnosis for prostate cancer among professors of the school of medicine, Minas Gerais Federal University- Brazil. Rev Assoc Med Bras. 2004;50:272-5.

15. Lurie N, Margolis KL, McGovern PG, Mink PJ, Slater JS. Why do patients of female physicians have higher rates of breast and cervical cancer screening? J Gen Intern Med. 1997;12:34-43. 